\author{
주택용 전력에 대한 지불의사액 분석 \\ 임슬예 · 김호영 · 유승훈 \\ 서울과학기술대학교 에너지환경대학원 에너지정책학과 \\ (2013년 5월 10일 접수, 2013년 6월 8일 수정, 2013년 6월 8일 채택)
}

\title{
Households' willingness to pay for the residential electricity use
}

\author{
Lim Seul-Ye $\cdot$ Kim Ho-Young · Yoo Seung-Hoon ${ }^{\dagger}$ \\ Department of Energy Policy, Graduate School of Energy \& Environment,Seoul National University of \\ Science \& Technology \\ (Received 10 May 2013, Revised 8 June 2013, Accepted 8 June 2013) \\ 요 약 \\ 전력은 인간생존에 있어 기본적인 요소이다. 본 논문에서는 주택용 전력에 대한 가구의 지불의사액 \\ (WTP)을 분석하고자 한다. 주택용 전력에 대한 WTP는 전력의 실제 가격과 추가적인 WTP의 합으로 \\ 정의된다. 전자는 시장에서 쉽게 관측되지만, 후자는 시장에서 관측이 불가능하므로 직접적인 가구조 \\ 사를 통해 추정해야만 한다. 이를 위해 2010년 11월 전국 1,000가구를 대상으로 조사를 실시하였다. \\ 분석 결과 주택용 전력 한 단위에 대한 추가적인 평균 WTP는 11.24 원 $/ \mathrm{kWh}$ 로 나타났다. 조사시점인 \\ 2010년 주택용 전력 평균가격은 98.07 원 $/ \mathrm{kWh}$ 이므로 주택용 전력에 대한 경제적 편익은 이 둘의 합계 \\ 인 109.31 원 $/ \mathrm{kWh}$ 으로 추정된다. 이 값은 주택용 전력 $1 \mathrm{kWh}$ 공급비용과 비교할 수 있을 것이다.
}

주요어 : 조건부 가치측정법, 주택용 전력, 경제적 편익, 스파이크모형

\begin{abstract}
Electricity is a basis for human existence. This paper attempts to analyze the households' willingness to pay (WTP) for the residential electricity use. The WTP for the residential electricity use can be defined as the sum of actual price of and additional WTP for it. The former is easily observed in the market, but the second is not observed and thus should be obtained through a WTP survey of households. To this end, this study conducted a survey of randomly selected 1,000 households in Korea in November 2010. The results indicate that the mean additional WTP for the residential electricity use was estimated to be KRW 11.24 per kWh. Given that the average price of residential electricity was KRW 98.07 per kWh at the time of the survey, the economic benefit from the residential electricity use was computed as KRW 109.31 per $\mathrm{kWh}$. This information can be compared with the cost involved in the supply of one $\mathrm{kWh}$ of residential electricity.
\end{abstract}

Key words : willingness to pay, residential electricity, economic benefit, average price

\section{1. 서 론}

전력은 인간생존에서 매우 중요하고 기본적인 요

\footnotetext{
${ }^{\dagger}$ To whom corresponding should be addressed.

Department of Energy Policy, Graduate School of Energy \&

Environment, Seoul National University of Science \&

Technology

Tel : 02-970-6802 E-mail : shyoo@seoultech.ac.kr
}

소이다. 최근 급격한 전전화로 인해 우리나라 전력소 비량은 매년 계속하여 증가하고 있다. 우리나라 주택 용 전력소비량은 1964년 967GWh에서 2010년에는 $61,194 \mathrm{GWh}$ 로 연평균 성장률이 $9.44 \%$ 에 이른다. 이 렇게 주택용 전력의 소비량은 계속해서 증가하는데 비해 전력 생산량은 그에 따른 즉각적인 반응을 보이 기가 어렵다. 왜냐하면 공급량 증대를 위한 시설 건 설에는 막대한 비용과 오랜 시일이 소요되고 수요관 
리의 중요요소인 가격인 전력요금은 조정이 쉽지 않 다. 전력은 일반적인 재화와 달리 독점적으로 공급이 이루어지고 있으며 가격은 대개의 시장재화와 달리 정책의 영향을 크게 받는다. 일반적으로 재화의 가격 은 그 재화의 가치를 반영하기 마련인데, 전기요금의 경우에는 정책적인 이유로 생산원가에 미치지 못하는 상황이다.

전력공급의 증대를 위해서는 막대한 정부예산이 소요되므로 관련 사업에 대한 경제성 분석은 사전에 필수적으로 요구된다. 우리나라 전력 소비구조를 살 펴보면 주택용이 $14 \%$, 일반용이 $33 \%$, 산업용이 $53 \%$ 로 나뉘어져 있다. 주택용 전력은 수용가에게 다양한 편익을 제공하지만 가치가 명시적으로 평가되지 못하 고 있는 실정이다. 가격인 주택용 전력요금은 정책적 통제 하에 있으므로 안정적인 주택용 전력공급으로 인해 발생하는 편익이 정확하게 반영되기 어렵다.

Austin(2011)은 나이지리아에서 안정적인 전력 공 급에 대한 가구의 추가적인 지불의사액(WTP)을 추 정하였다. 또한 전력의 공급관리측면이 아닌 수요관 리측면에서 접근하여 개발도상국에서의 합리적 가격 수준을 제시하였다. 이러한 상황에서 본 논문은 우리 나라의 주택용 전력의 경제적 가치를 추정하는 이론 적 틀을 제시하고, 주택용 전력과 관련된 사업의 의 사결정에서 필요한 정보를 제공하고자 한다.

본 논문에서는 전국의 1,000 가구를 대상으로 실시 한 설문조사 자료를 활용하여 주택용 전력에 대한 추 가적인 WTP를 추정한다. 이후 추정된 WTP를 활용 하여 주택용 전력의 경제적 가치를 서술한다. 본 논 문의 이후 부분은 다음과 같이 구성된다. 제2절에서 는 주택용 전력 편익 추정방법에 대해서 논의한다. 제3절에서는 WTP모형을 설명한다. 분석에 활용된 자료 및 주요 분석결과는 제4절에서 다룬다. 마지막 으로 제 5 절에서는 연구결과를 요약하고 정책적 시사 점을 도출한다.

2. 경제적 편익 추정방법론: 조건부 가치측정법

주택용 전력의 수요에서 총 WTP는 주택용 전력 수요곡선의 아랫면적을 의미한다. 소비자 잉여는 보 통수요곡선의 아랫면적과 시장가격 혹은 소비자가 지 출한 금액의 윗면으로 정의된다. 즉, 주택용 전력소비 의 경제적 가치는 소비자잉여와 실제 소비자 지출의 합과 같다. 다시 말하면, 어떤 가격에서 전력이 소비
될 때, 경제적 가치 혹은 전력소비의 편익은 실제 전 력가격과 추가적인 WTP액의 합으로 계산할 수 있다. 본 논문은 얼마나 많은 사람들이 주택용 전력소비에 대해 추가적인 지불의사가 있는지에 대해 조건부 가 치측정법(CVM: Contingent Valuation Method)을 적 용하여 추정한다. $\mathrm{CVM}$ 은 특히 자원이나 기술 등과 같은 비시장재화의 편익을 측정하는데 널리 사용되는 기법이다. Woo and Pupp(1992)은 전력 소비자들에 게 서비스공급지장비용에 대해 적용하였고, Borchers et al.(2007)는 신재생에너지로 생산된 전력에 대한 WTP를 제시하였다. Grösche and Schröder(2011)는 전력을 신재생에너지원으로 생산할 때 공공지원에 대 하여 연구하였다.

미국의 National Oceanic and Atmospheric Administration (NOAA) 패널은 " $\mathrm{CVM}$ 이 비사용가 치를 포함하여 피해를 법적으로 평가하는 출발점이 되기에 충분히 믿을만한 추정치를 제공할 수 있다"고 결론을 내렸다. (Arrow et al., 1993) Fisher(1996)는 $\mathrm{CVM}$ 이 전통적 미시경제이론에 잘 부합하는 것으로 보았고, Vehkatachalam(2004)는 광범위한 문헌연구 를 통하여 CVM이 유용한 정보를 제공할 수 있다고 하였다. 본 논문에서는 $\mathrm{CVM}$ 의 타당성과 정확도를 향상시키기 위하여 NOAA 패널이 제시한 지침을 따 랐다. 지침에 의하면 응답자가 재화에 친숙하거나 해 당 재화와 지불수단이 응답자에게 정확하게 이해했을 경우, 또는 전문조사원이 조사를 시행하면 CVM 타 당성과 정확도가 향상된다. 또한 응답자가 충분히 이 해할 수 있도록 하기 위하여 일대일 개별면접 설문을 실시하였다.

\section{WTP모형}

\section{3-1 효용격차모형}

Hanemann(1984)의 효용격차모형을 이용하면 양분 선택형 조건부 가치측정(DC-CV: dichotomous choice contingent valuation) 자료로부터 각 개인의 힉스적 보상잉여를 도출할 수 있다. 응답자가 자신의 효용함수를 정확하게 알고, 주어진 화폐소득 $(m)$ 과 개인의 특성벡터 $(S)$ 에 근거하여 주택용 전력의 소비 상태 $(j)$ 에 대해 느끼는 효용은 간접효용함수 $u$ 로 표 현된다.

$$
u=u(j, m ; S), j=0,1
$$


이때 $j$ 값인 0 과 1 은 각각 응답자의 주택용 전력 소비여부를 나타낸다. $j=0$ 은 주택용 전력을 소비하 지 못하는 상태를 의미하며 $j=1$ 은 주택용 전력을 소비하는 상태를 의미한다. 이때 연구자가 관측 불가 능한 부분이 존재하므로 간접효용함수는 다음과 같이 관측 가능한 확정적인 부분 $v(j, m ; S)$, 관측 불가능 한 확률적 부분 $\epsilon_{j}$ 로 구성한다.

$$
u(j, m ; S)=v(j, m ; S)+\epsilon_{j}
$$

만약 응답자가 “당신은 주택용 전력을 소비하기 위 해 현재의 가격 이외에 $A$ 원을 추가적으로 지불할 의 사가 있습니까?"라는 질문에 대해 "예" 라고 응답하 는 경우, $A$ 원을 기꺼이 지불함으로써 효용을 최대화 한다.

$$
v(1, m-A ; S)+\epsilon_{1} \geq v(0, m ; S)+\epsilon_{0}
$$

또는

$$
v(1, m-A ; S)-v(0, m ; S) \geq \epsilon_{0}-\epsilon_{1}
$$

효용의 격차와 오차항의 격차를 다음과 같이 정의 한다.

$$
\Delta v(A) \equiv v(1, m-A ; S)-v(0, m ; S)
$$

$\eta$ 는 효용격차의 분포를 정형화하기 위한 확률변수 이다.

$$
\eta=\epsilon_{0}-\epsilon_{1}
$$

각 응답자는 주택용 전력을 통해 얻을 수 있는 간 접효용의 증가분 $(\Delta v)$ 이 양 $(+)$ 이면 '예’라고 답하고 제시금액의 지불에 대해 동의하는 것으로 개인의 효 용을 증가시킬 것이다. 따라서 응답자가 '예' 라고 응 답을 할 확률은 다음의 식(7)과 같다.

$$
\begin{gathered}
\operatorname{Pr}(Y e s)=\operatorname{Pr}\{\Delta v(A) \geq \eta\} \equiv F_{\eta}[\Delta v(A)] \quad \text { (7) } \\
F_{\eta}(\cdot) \text { 는 확률변수 } \eta \text { 의 누적분포함수 }(\mathrm{cdf},
\end{gathered}
$$

cumulative distribution function)이다. 그런데 응답자 가 실제로 지불의사질문에 대해 '예'라는 응답을 하 였다면 확률변수인 지불의사액 $C$ 는 $G_{c}(A)$ 로 정의 된다. 한편 식(7)은 다음과 같이 정리할 수 있다.

$$
\operatorname{Pr}(Y e s)=\operatorname{Pr}\{C \geq A\} \equiv 1-G_{c}(A)
$$

따라서 $\eta$ 의 누적분포함수는 다음의 식(8)과 같이 나타낼 수 있다. 여기서 $G_{c}(A)$ 는 확률변수 $C$ 의 누 적분포함수이며, $A$ 는 제시금액이다.

$$
1-G_{c}(A) \equiv F_{\eta}[\Delta v(A)]
$$

Hanemann(1984)의 지적에 따르면 식(4)는 확률효 용이론의 맥락에서 효용극대화 응답으로 해석될 수 있고, $G_{c}(\cdot)$ 는 개인의 참 최대 $\mathrm{WTP}$ 의 누적분포함수 가 된다. 결국, WTP모형을 추정한다는 것은 누적분 포함수 $G_{c}(\cdot)$ 의 모수를 추정하는 것을 의미한다.

\section{3-2 단일경계모형}

우선 제시된 금액에 대해 지불의사가 있는 지 여부 를 묻는 질문에 대한 응답을 모형화한다. 즉, '예' 또 는 '아니오'의 이산응답을 모형화한 후 최우추정법을 통해 관련된 모수들을 추정한다. 다음 단계로 분포의 성격과 평균값 또는 중앙값의 정의를 이용하여 WTP 의 평균값 또는 중앙값을 계산한다. $i=1, \ldots, N$ 는 표 본에서 각각의 응답자들을 지수화 한 것이다. 각각의 응답자들이 제시금액에 대해 각각 (1) ‘예', (2) ‘아니 오'로 응답하는데 $I_{i}^{Y}$ 와 $I_{i}^{N}$ 와 같이 나타낼 수 있다..

$$
\begin{aligned}
& I_{i}^{Y}=1(i \text { 번째 응답자의 응답이 '예' }) \\
& I_{i}^{N}=1(i \text { 번째 응답자의 응답이 '아니오' })
\end{aligned}
$$

여기서 $1(\cdot)$ 는 인디케이터함수(indicator function) 이다. 즉, $1(\cdot)$ 의 괄호 안이 조건이 만족되면 1 을 취 하고, 아니면 0 을 취한다. 효용극대화를 추구하는 $N$ 명의 표본을 가정할 경우 로그-우도함수 (log-likelihood function)는 다음과 같이 표현된다.

$$
\ln L=\sum_{i=1}^{N}\left\{I_{i}^{Y} \ln \left[1-G_{c}(A)\right]+I_{i}^{N} \ln \left[G_{c}\left(A_{i}\right)\right]\right\}
$$




\section{3-3 스파이크모형}

일반국민들을 대상으로 주택용 전력의 공급에 대 해 물었을 때, 본인의 소비를 일부러 줄여가면서 일 정금액을 추가적으로 지불한다는 것에 대해 거절 의 사를 가지고 있는 사람이 적지 않다. 즉, 응답자들은 영(0)의 WTP를 가질 수 있다. 하지만 기존의 통상적 선형모형은 영(0)의 WTP가 존재하는 사실을 모형 내에 명시적으로 반영하는 것이 어렵다. 왜냐하면 $\mathrm{WTP}$ 의 분포함수는 연속이므로 특정 점, 즉 0 에서의 점질량(point mass)은 0 이기 때문이다. 아울러 제시 금액에 대해 '아니오'란 응답이 많은 경우에는 평균 WTP 추정값이 음수이면서 통계적으로 유의하게 추 정되어 후생분석이 불가능한 경우가 왕왕 발생하며, 본 연구에서 사용한 자료에서도 이러한 상황이 발생 하였다.

후술하겠지만 응답자의 $64.6 \%$ 는 지불의사가 전혀 없다고 응답하였다. 이러한 경우에는 Kriström(1997) 및 Yoo and Kwak(2002)에서 논의되었듯이 스파이 크 모형의 적용이 유용하다. 스파이크 모형은 영 $(0)$ 의 WTP를 명시적으로 반영할 수 있는 장점을 가진다. 물론 스파이크 모형 이외에도 혼합모형 등 다른 모형 의 적용이 가능하긴 하지만 본 논문에서는 적용이 가 능한 여러 모형 중에서 스파이크 모형을 적용하고자 한다.

따라서 이러한 경우에 모형에 투입될 적절한 자료 확보를 위해 설문지 또한 보완이 필요하다. 이때 본 연구에서는 설문지에 단 1 원의 지불의사도 없는지를 묻는 질문을 포함하였다. 그리하여 주택용 전력을 공 급받는 것에 대한 단일경계 스파이크모형의 $i$ 번째 응 답자가 직면하는 응답상황은 식(12)와 같이 세 가지 로 정리된다.

$I_{i}^{Y}=1(i$ 번째 응답자의 응답이 '예' $)$

$I_{i}^{N Y}=1(i$ 번째 응답자의 응답이 '아니오 - 예' $)$

$I_{i}^{N N}=1(i$ 번째 응답자의 응답이 '아니오 - 아니오' $)$

제시금액이 $A$ 일 경우 응답자는 (1) '예', (2) ‘아니 오-예', (3) ‘아니오-아니오'라고 응답할 수 있다. 효 용극대화를 추구하는 $N$ 명의 표본을 가정할 경우 로 그-우도함수(log-likelihood function)는 다음과 같이 표현된다.

$$
\ln L=\sum_{i=1}^{N}\left\{\begin{array}{l}
I_{i}^{Y} \ln \left[1-G_{c}(A)\right]+ \\
I_{i}^{N Y} \ln \left[G_{c}\left(A_{i}\right)-G_{c}(0)\right]+I_{i}^{N N} \ln \left[G_{c}(0)\right]
\end{array}\right\}
$$

여기서 $1(\cdot)$ 는 인디케이터함수(indicator function) 이다. 즉, $1(\cdot)$ 의 괄호 안이 조건이 만족되면 1 을 취 하고, 아니면 0 을 취한다. $\mathrm{WTP}$ 의 누적분포함수를 $G_{c}(\cdot ; \theta)$ 라 하고 이를 로지스틱(logistic) 함수로 가 정하여 스파이크 모형을 구성하면 평균값 $\mathrm{WTP}$ 를 추 정할 수 있다. 스파이크 모형에 있어서, $\theta=(a, b)$ 일 때 WTP의 누적분포함수는 식 (14)와 같이 정의된다.

$$
G_{c}(A ; \theta)= \begin{cases}{[1+\exp (a-b A)]^{-1}} & \text { if } A>0 \\ {[1+\exp (a)]^{-1}} & \text { if } A=0 \\ 0 & \text { if } A<0\end{cases}
$$

이때 스파이크는 $1 / \ln [1+\exp (a)]$ 로 정의되며 표 본에서 영(0)의 WTP를 갖는 응답자의 비중을 의미 한다. 한편 평균값 $\mathrm{WTP}$ 는 식(15)와 같이 추정된다.

$$
\overline{W T P}=(1 / b) \ln [1+\exp (a)]
$$

\section{4. 분석결과}

\section{4-1. 설문결과}

본 연구에서 사용되는 주택용 전력공급에 대한 우리나라 가구의 WTP는 2010년 11월에 수집되었다. Table 1은 단일경계 양분선택형 질문에 대한 응답의 분포를 나타내고 있다. 전체 1,000 가구를 대상으로 설문을 실시하였으며 전체 응답자 중 $64.6 \%$ 에 해당 하는 646 가구는 주택용 전력공급에 대해 추가적인 지불의사가 전혀 없다고 응답하였다. 절반 이상의 응 답자들이 영 $(0)$ 의 WTP로 응답하였으므로, 이를 반영 할 수 있는 모형인 스파이크 모형의 적용이 적절하다.

\section{4-2. 단일경계 스파이크모형의 추정결과문결과}

단일경계 스파이크모형의 추정결과는 Table 2에 제시되어 있다. 전국 1,000 가구를 대상으로 설문을 실시하였으며 추정계수는 유의수준 $1 \%$ 에서 통계적 으로 유의하다. Wald 통계량이 유의수준 $1 \%$ 에서 유 의하므로 추정방정식에 있는 모든 추정계수들의 값이 0 이라는 귀무가설이 기각된다. 한편 스파이크는 유의 
Table 1. Distribution of responses by each bid amount

\begin{tabular}{c|c|c|c|c}
\hline \multirow{2}{*}{ Bid amount in KRW } & \multirow{2}{*}{ Sample size } & \multicolumn{3}{|c}{ Number of responses (\%) } \\
\cline { 3 - 5 } & & 'yes' votes & 'no-yes' votes & 'no-no' votes \\
\hline \hline 5 & $128(100.0 \%)$ & $50(39.1 \%)$ & $4(3.1 \%)$ & $74(57.8 \%)$ \\
\hline 10 & $128(100.0 \%)$ & $37(28.9 \%)$ & $7(5.5 \%)$ & $84(65.6 \%)$ \\
\hline 15 & $125(100.0 \%)$ & $27(21.6 \%)$ & $22(17.6 \%)$ & $76(60.8 \%)$ \\
\hline 20 & $124(100.0 \%)$ & $26(21.0 \%)$ & $15(12.1 \%)$ & $83(66.9 \%)$ \\
\hline 25 & $127(100.0 \%)$ & $18(14.2 \%)$ & $22(17.3 \%)$ & $87(68.5 \%)$ \\
\hline 30 & $123(100.0 \%)$ & $19(15.4 \%)$ & $24(19.5 \%)$ & $80(65.0 \%)$ \\
\hline 40 & $124(100.0 \%)$ & $17(13.7 \%)$ & $28(22.6 \%)$ & $79(63.7 \%)$ \\
\hline Totals & $121(100.0 \%)$ & $8(6.6 \%)$ & $30(24.8 \%)$ & $83(68.6 \%)$ \\
\hline & $1,000(100.0 \%)$ & $202(20.2 \%)$ & $152(15.2 \%)$ & $646(64.6 \%)$ \\
\hline
\end{tabular}

Table 2. Estimation results of the spike model without covariates

\begin{tabular}{|c|c|}
\hline Variables & Coefficient estimates \\
\hline Constant & $-0.599(-9.08)^{*}$ \\
\hline Bid amount $^{\mathrm{a}}$ & $-0.039(12.87)^{*}$ \\
\hline Spike & $0.646(42.74)^{*}$ \\
\hline Number of observations & 1,000 \\
\hline Log-likelihood & -854.49 \\
\hline Wald statistic ${ }^{\mathrm{b}}$ ( $p$-value) & $1,826.70(0.000)$ \\
\hline
\end{tabular}

Notes: ${ }^{\mathrm{a}}$ The unit is Korean won. ${ }^{\mathrm{b}}$ The null hypothesis is that all the parameters are jointly zero and the corresponding $p$-value is reported in the parentheses beside the statistic. *indicates the statistical significance at the $1 \%$ level. The numbers in parentheses beside the coefficient estimates are $t$-values.

Table 3. Estimation results of the mean WTP

\begin{tabular}{c|c}
\hline Variables & Estimates \\
\hline \hline Mean additional WTP & KRW 11.31 \\
\hline$t$-value & $11.69^{*}$ \\
\hline $95 \%$ confidence interval $^{\mathrm{a}}$ & 9.63 to 13.41 \\
\hline $99 \%$ confidence interval ${ }^{\mathrm{a}}$ & 9.20 to 14.18 \\
\hline $\begin{array}{l}\text { Notes: }{ }^{\mathrm{a}} \text { The confidence intervals are calculated by the use } \\
\text { of the Monte Carlo simulation technique of Krinsky } \\
\text { and Robb(1986) with 5,000 replications. * indicates } \\
\text { the statistical significance at the } 1 \% \text { level. }\end{array}$
\end{tabular}

수준 $1 \%$ 에서 통계적으로 유의하며 0.646 으로 추정되 었다. 응답자가 실제로 영 $(0)$ 의 WTP를 밝힌 비중은 $64.6 \%$ 로 스파이크의 값은 영 $(0)$ 의 WTP를 밝힌 표본 비율과 유사함을 알 수 있다. 따라서 스파이크도 적 절하게 추정되었다.

단일경계 스파이크 모형의 추정결과와 식 (13)을 이용하여 구한 평균 WTP의 추정값은 Table 3에 요 약되어 있다. 분석결과 전체 가구당 추가적인 평균 지불의사액(Mean additional WTP)은 11.24원이었고, $t$-값은 11.69 로 추정된 추가적인 평균 $\mathrm{WTP}$ 는 유의 수준 $1 \%$ 에서 통계적으로 유의하다.

추가적인 평균 WTP 추정에 수반된 불확실성을 반 영한 신뢰구간의 계산을 위해 Krinsky and $\operatorname{Robb}(1986)$ 이 제안한 모수적 부트스트랩(parametric bootstrap) 기법인 몬테칼로 시뮬레이션 기법을 적용 하였다. 무작위 반복표본추출의 회수는 5,000 번으로 하였으며, $95 \%$ 신뢰구간 및 $99 \%$ 신뢰구간을 Table 3 에 정리하였다. 몬테칼로 시뮬레이션 기법의 적용 절차는 다음과 같다. 우선 $(a, b)$ 의 추정치와 이에 대 한 분산-공분산 행렬을 이용하여 $(a, b)$ 의 다변량 정 규분포로부터 $(a, b)$ 의 값을 발생시켜 평균 $\mathrm{WTP}$ 를 계산하며 이 과정을 5,000 번 반복한다. 이렇게 발생 된 5,000개의 평균 WTP 값을 크기순으로 나열한 다 음 양끝에서 각각 $2.5 \%$ 를 버리면 $95 \%$ 신뢰구간을 얻을 수 있으며, 양끝에서 각각 $0.5 \%$ 를 버리면 $99 \%$ 신뢰구간을 얻을 수 있다.

전국의 1,000 가구를 대상으로 설문을 실시하여 추 가적인 WTP를 추정하였다. Table 4에 추정결과에 
Table 4. Table 1. Additional WTP and economic value of residential electricity

\begin{tabular}{c|c|c|c}
\hline Unit values & Average price & Additional WTP & Total economic value of residential electricity \\
\hline \hline Estimates & $\begin{array}{c}98.07 \mathrm{won} \\
\text { per } \mathrm{kWh}\end{array}$ & $\begin{array}{c}11.31 \mathrm{won} \\
\text { per } \mathrm{kWh}\end{array}$ & $\begin{array}{c}109.38 \mathrm{won} \\
\text { per } \mathrm{kWh}\end{array}$ \\
\hline
\end{tabular}

의하면 주택용 전력의 평균가격은 98.07 원 $/ \mathrm{kWh}(2010$ 년 기준)이고 추가적인 WTP는 11.24 원 $/ \mathrm{kWh}$ 로 추정 되었다. 즉, 주택용 전력공급에 대해 우리나라 가구당 매월 평균적으로 11.24 원 $/ \mathrm{kWh}$ 의 추가적인 $\mathrm{WTP}$ 를 가지고 있었다. 그리고 주택용 전력의 경제적 가치는 109.31원 $/ \mathrm{kWh}$ 으로 계산되었다.

\section{5. 결론 및 정책적 시사점}

우리나라 산업 및 경제에서 전력은 매우 중요하고 필수적인 요소이다. 특히 주택용 전력은 일반 국민들 의 생활에서 다양한 편익을 제공하고 있다. 지금까지 전력의 편익 추정에 관한 여러 방법론의 논의가 있어 왔다. 이 때 본 논문은 얼마나 많은 사람들이 주택용 전력소비에 대해 추가적인 지불의사가 있는지에 대해 $\mathrm{CVM}$ 을 적용하여 추정한다. 전력은 시장에서 거래되 는 재화이지만, 가격인 전력요금이 정책에 의해 큰 영향을 받는다. 현재 우리나라의 전력 $1 \mathrm{kWh}$ 의 가격 은 생산원가보다 낮아 편익의 과소추정 우려가 존재 한다. 주택용 전력의 편익을 평가하기 위해서는 엄밀 한 경제이론에 근거하여 과학적으로 추정할 필요가 있다. 이에 따라 본 논문에서는 $\mathrm{CVM}$ 을 적용하여 주 택용 전력의 경제적 편익 추정한다.

전력을 소비할 때, 경제적 가치 혹은 전력소비의 편익은 실제 전력가격과 추가적인 WTP의 합으로 계 산할 수 있다. 이 때 지불의사 유도방법으로 단일경 계 모형을 적용하여 설문조사를 수행하고 추정하여 결과를 도출하였다. 아울러 $\mathrm{CVM}$ 을 적용하는 데 있 어서, Arrow et al.(1993)의 여러 가지 지침에 근거 하여 설문이 수행되었다. 본 논문에서는 단일경계모 형을 활용하였고, 영(0)의 WTP를 명시적으로 다룰 수 있는 스파이크 모형을 적용하였다. 스파이크 모형 을 적용한 추가적인 WTP의 평균값은 유의수준 $1 \%$ 에서 통계적으로 유의한 것으로 나타났다.

주택용 전력의 경제적 가치는 109.31 원 $/ \mathrm{kWh}$ 으로
나타났고, 이는 주택용 전력 $1 \mathrm{kWh}$ 공급을 위해 소요 되는 비용과 비교할 수 있는 정보이다. 비용 및 편익 정보를 이용하여 주택용 전력 공급에 관련된 프로젝 트의 경제적 타당성 분석과 관련된 의사결정에서 유 용하게 적용될 수 있다. 예를 들어 주택용 전력 공급 을 증대하는 사업을 시행하기 위해서는 막대한 예산 이 소요되므로, 주택용 전력 공급의 경제적 편익을 정량적으로 분석한 후 사업의 경제적 타당성 여부를 평가해야 한다. 또한 국민들의 사회적 후생에 기여하 는 주택용 전력은 명확한 목표 아래 종합적인 관리시 스템 하에서 운영되고 경제적 자원으로써 다뤄져야 할 것이다.

\section{참고문헌}

1. 한국전력공사, www.kepco.co.kr

2. Arrow K, Solow R, Portney PR, Leamer EE, Radner R, Schuman H. Report of the NOAA panel on contingent valuation. Federal Register, 1993, 58, 4601-4014.

3. Austin C, Otegbulu. A contingent valuation model for assessing electricity demand. Journal of Financial Management of Property and Construction, 2011, 16, 126-146.

4. Borchers AM, Duke JM, Parsons GR. Does willingness to pay for green electricity differ by source Energy Policy 2007;35:3327-34.

5. Fisher A. The conceptual underpinnings of the contingent valuation method. in: Bjornstad DJ, Kahn JR (eds) The Contingent Valuation of Environmental Resources. Cheltenham: Edward Elgar, 1996, 19-37.

6. Grösche P, Schröder C. Eliciting public support for greening the electricity mix using random parameter technique. Energy Economics 2011;33:363-70. 
7. Hanemann WM. Welfare evaluations in contingent valuation experiments with discrete responses. American Journal of Agricultural Economics, 1984, 66, 332-341.

8. Krinsky I, Robb AL. On approximating the statistical properties of elasticities. Review of Economics and Statistics, 1986, 68, 715-719.

9. Kriström B. Spike models in contingent valuation. American Journal of Agricultural Economics, 1997, 79, 1013-1023.

10. McFadden D. Contingent valuation and social choice. American Journal of Agricultural Economics, 1994, 76, 689-708.

11. Vehkatachalam L. The contingent valuation method: a review. Environmental Impact Assessment Review, 2004, 24, 89-124.

12. Woo CK, Pupp RL. Costs of service disruptions to electricity consumers. Energy 1992;17:109-26.

13. Yoo SH, Kwak SJ. Using a spike model to deal with zero response data from double bounded dichotomous contingent valuation survey. Applied Economics Letters, 2002, 9, 929-932. 